\title{
Right-turn Bypass Lanes at Roundabouts: Geometric Schemes and Functional Analysis
}

\author{
Raffaele Mauro $^{1} \&$ Marco Guerrieri ${ }^{2}$ \\ ${ }^{1}$ University of Trento, Department of Civil, Environmental and Mechanical Engineering, Trento, Italy \\ ${ }^{2}$ University of Enna “Kore”, Faculty of Engineering and Architecture, Enna, Italy \\ Correspondence: Marco Guerrieri, University of Enna "Kore", Faculty of Engineering and Architecture, Via della \\ Cooperazione, Enna Bassa 94100, Enna, Italy. Tel: 39-935-536-350. E-mail: marco.guerrieri@tin.it
}

\author{
Received: November 8, 2012 Accepted: December 3, $2012 \quad$ Online Published: December 7, 2012 \\ doi:10.5539/mas.v7n1p1 \\ URL: http://dx.doi.org/10.5539/mas.v7n1p1
}

\begin{abstract}
Right-turn bypass lanes can be implemented in conventional and innovative roundabout intersections to increase the capacity and improve the global functional performances. The Right-turn bypass lanes (also called slip lanes) can be distinguished according to the planimetric layout and the entry control type (stop, yield slip or Free Flow acceleration lane). This paper presents a closed-form model for the estimation of capacity, delays and level of service of roundabout equipped with Right-turn bypass lanes, considering the effect of geometric slip lane schemes, control type, vehicular and pedestrian flow. In order to examine the traffic conditions which can benefit from slip lane roundabouts in terms of capacity and delays, compared to traditional schemes which have no additional lanes, a great number of analyses have been carried out by considering different $\mathrm{O} / \mathrm{D}$ matrices and vehicle and pedestrian flow vectors. Such comparisons have been made by considering the control delays in function of different O/D matrices. Such O/D matrices describe the most significant situations of traffic demand which can be of interest for the road intersections under study.
\end{abstract}

Keywords: right-turn bypass lanes, geometric layout, capacity, delay and level of service

\section{Introduction}

It is known that in case of heavy right-turn flows, slip lanes can be implemented to increase the compact and mini single-lane roundabout capacity (NCHRP Report 672, 2010) (see Figure 1a). The additional right-turn slip lanes are also used to configure turbo roundabouts (Turborotondes - CROW, 2008; Fortuijn, 2009) and flower roundabouts (Tollazzi et al., 2011; Al-Ghandour et al., 2012) (see Figures 1b and 1c). In flower roundabouts actually the geometry and performance are characterized by slip lanes at each leg (Tollazzi et al., 2011). In urban and sub-urban areas, with bicycle and pedestrian activity, a right-turn bypass lane should be implemented only where needed because the entries and exits of bypass lanes can increase conflicts with pedestrians, bicyclists and with merging on the downstream leg. However, in locations with low pedestrian and bicycle activity, slip lanes can be used to improve capacity when heavy right-turning traffic exists (NCHRP Report 672, 2010; FHWA, 2004).

There are various right-turn slip lane types. They can be distinguished according to the planimetric layout, the position respect to the ring lane, the merging modes with the roundabout entry leg and the entry control type into the roundabout exit leg. As for the control type, there are stop and yield slip lanes (Figure 2), different from those with an acceleration lane (Figure 4). The guidelines for design the geometric elements of slip lanes have been provided by kinematic considerations and by taking into account the waiting phenomena in the end sections. For details on the different slip lanes configurations, see NCHRP Report 672 and HCM 2010, as examples.

In this paper we are examined the geometric schemes of slip lanes shown in Figures 2 and 4. The slip lane type has effects on the global roundabout performance which can be also very different. A crucial role in bringing about these effects is played by the control type of exit flows from a slip lane. The capacity determination, the queue lengths and delays (measures of effectiveness, MOE) in right-turn slip lane roundabouts generally is carried out through traffic micro simulation (Al-Ghandour et al., 2012). This paper will show that, as a matter of fact, by considering the results developed as closed-form expressions through the queuing theory, it is possible to estimate if and which effects the slip lane geometry and control type (e.g. slip lane composition and length) can 
have on roundabout MOE. The calculation model developed in this paper includes the various single-lane roundabout types equipped with right-turn slip lanes controlled by stop or yield signs or with an acceleration lane ("Free Flow slip lane"). Moreover, in order to identify the traffic conditions which justify more considerable financial costs to build slip lanes (Mauro \& Cattani, 2012) a great number of comparisons have been made between the different geometric patterns. Such comparisons have been made by considering the vehicles delays in function of different O/D matrices. Such O/D matrices describe the most significant situations of traffic demand which can be of interest for the designs under study.

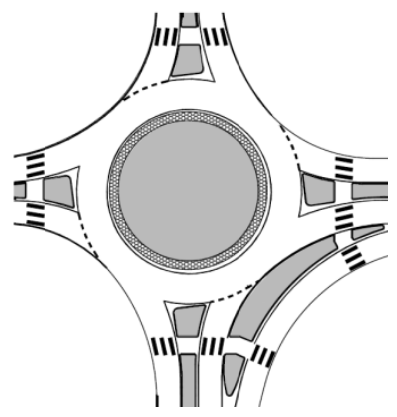

a) Bypass lane at conventional roundabout

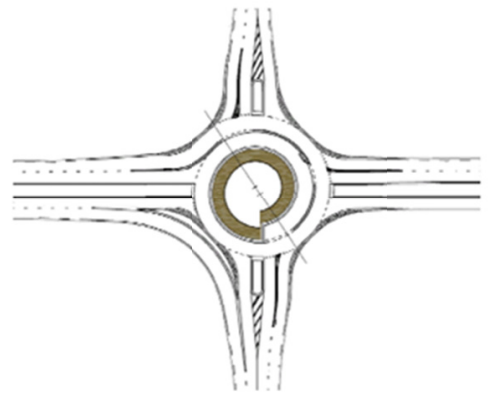

b) Bypass lane at turbo roundabout

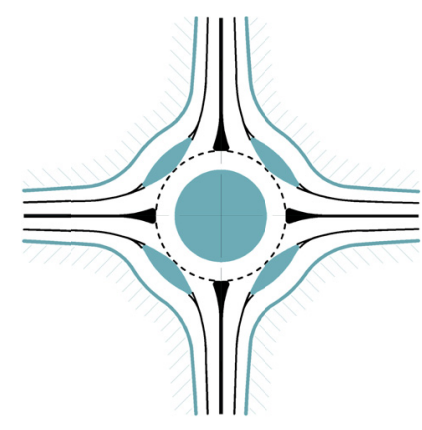

c) Bypass lane at Flower roundabout

Figure 1. Bypass lanes at roundabouts

\section{Slip Lane without an Acceleration Lane (with Stop or Yield Signs)}

This slip lane type has the same geometric design as in Figure 2. The total right-turn flow is denoted with $\mathrm{Q}_{\mathrm{E}, \mathrm{R}}$ while that one through the slip lane is indicated with $Q_{E, R}{ }^{\text {bypass }}$. The antagonist flow of $Q_{E, R}$ bypass exiting from the roundabout is denoted with $\mathrm{Qu}^{\text {Tot }}$. For instance, with reference to leg 4, in Figure 2, it follows that $\mathrm{Qu}^{\mathrm{Tot}}=\mathrm{Q}_{1,4}+$ $\mathrm{Q}_{2,4}+\mathrm{Q}_{\mathrm{E}, \mathrm{R}}{ }^{\text {no-bypass }} ; \mathrm{Q}_{\mathrm{E}, \mathrm{R}}{ }^{\text {no-bypass }}=\mathrm{Q}_{3,4}-\mathrm{Q}_{\mathrm{E}, \mathrm{R}}{ }^{\text {bypass }}$. It similarly occurs to $\mathrm{Qu}^{\text {Tot }}$ related to the other legs.

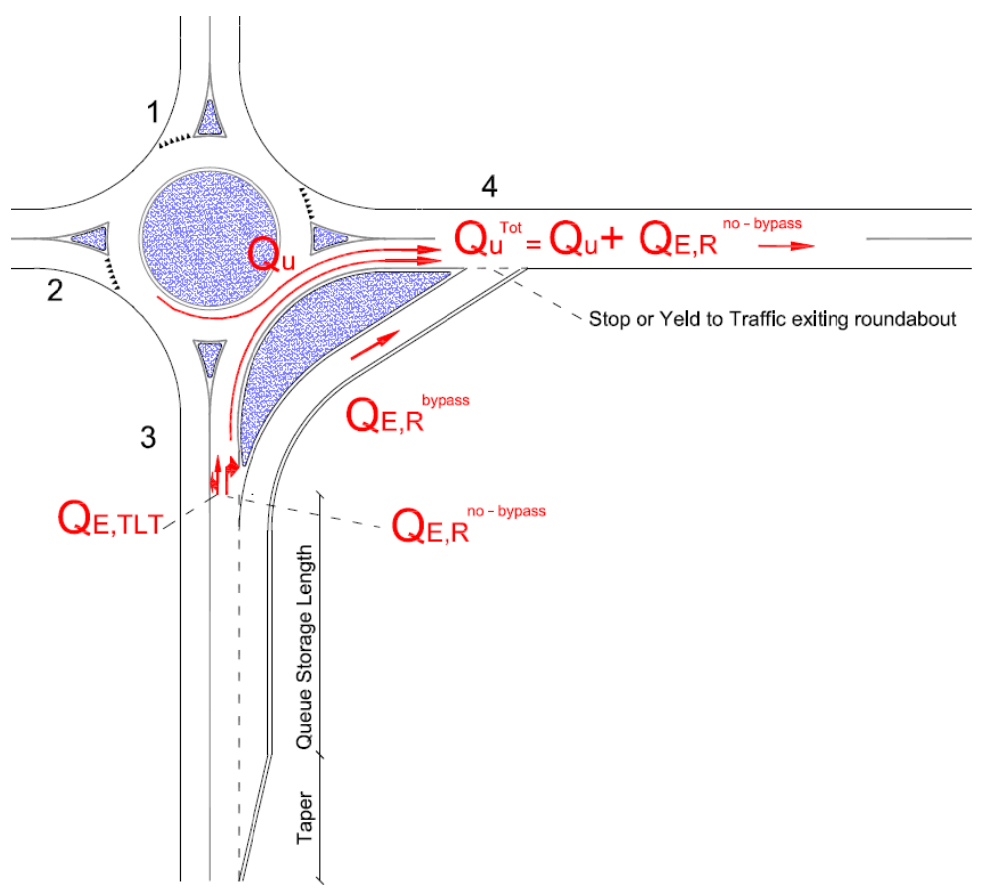

Figure 2. Entry, circulating and exit flows at roundabout (Stop or Yeld to traffic exiting)

\subsection{Slip Lanes with a Stop Sign}

In the absence of specific indications from the guidelines, let us determine the stop slip lane capacity $\mathrm{C}_{\mathrm{E}, \mathrm{R}}$ by means of some results from the Queuing Theory. Thus, $\mathrm{C}_{\mathrm{E}, \mathrm{R}}$ is equal to the reciprocal of the average $\mathrm{b}=\mathrm{E}[\mathrm{s}]$ of 
the service time $s$ estimated at the merging slip lane section into the leg coming from the roundabout. In the event of Poisson vehicle arrivals for $\mathrm{Q}_{\mathrm{E}, \mathrm{R}}{ }^{\text {bypass }}$, any service time $s$ and vehicle headways $\tau$ for the flow $\mathrm{Qu}^{\text {Tot }}$ distributed like a Gamma random variable with a parameter K (Mauro \& Branco, 2012), according to $P-K$ relationships (Pollaczek, 1930; Khinchine, 1932; Kleinlock, 1975), b = E[s] can be calculated as following:

$$
b=T+\frac{e^{K Q T}-\sum_{i=0}^{K} \frac{(K Q T)^{i}}{i !}}{Q \cdot \sum_{i=0}^{K-1} \frac{(K Q T)^{i}}{i !}}
$$

where: $\mathrm{T}=$ critical gap [s]; $\mathrm{Q}=\mathrm{Qu}^{\mathrm{Tot}}[\mathrm{veh} / \mathrm{h}] ; \mathrm{K}=1$ if $100 \leq \mathrm{Q} \leq 300 \mathrm{veh} / \mathrm{h} ; \mathrm{K}=2$ if $400 \leq \mathrm{Q} \leq 800 \mathrm{veh} / \mathrm{h} ; \mathrm{K}=3$ if $800 \leq \mathrm{Q} \leq 1500 \mathrm{veh} / \mathrm{h}, \mathrm{K}=4$ if $1500<\mathrm{Q} \leq 1800 \mathrm{veh} / \mathrm{h}$.

By means of (1) $\mathrm{C}_{\mathrm{E}, \mathrm{R}}$ follows as:

$$
C_{E, R}=\frac{1}{T+\frac{e^{K Q T}-\sum_{i=0}^{K} \frac{(K Q T)^{i}}{i !}}{Q \cdot \sum_{i=0}^{K-1} \frac{(K Q T)^{i}}{i !}}}
$$

The critical gap can be calculated by means of the following relation:

$$
T=\frac{V}{2 \cdot a}+2 \cdot \delta
$$

where $\mathrm{V}$ is the vehicle speed on $\mathrm{Qu}^{\mathrm{Tot}}, a$ the acceleration by which $\mathrm{Q}_{\mathrm{E}, \mathrm{R}}{ }^{\text {bypass }}$ vehicles enter into the flow $\mathrm{Qu}^{\text {Tot }}$; $\delta$ is the safety time interval between the vehicles of this flow, equal to the Perception-Reaction Time $\delta=1$ s. V can be calculated through the procedure shown in NCHRP Report 672 in function of deflection radius of the vehicle trajectories passing through ring lane $R_{2}$ and coming from ring lane $R_{3}$. For the dimensions of compact single-lane roundabouts considered in this paper, $R_{2}$ and $R_{3}$ are generally included in the intervals $12 \mathrm{~m} \leq \mathrm{R}_{2} \leq$ $18 \mathrm{~m}$ and $23 \mathrm{~m} \leq \mathrm{R}_{3} \leq 29 \mathrm{~m}$. With $\mathrm{R}_{2}$ and $\mathrm{R}_{3}$ values included in the previous intervals, $\mathrm{V}$ determinations near to $\mathrm{V}$ $=30 \mathrm{~km} / \mathrm{h}$ can be obtained. As for the vehicle merging manoeuvre of $\mathrm{Q}_{\mathrm{E}, \mathrm{R}}{ }^{\text {bypass }}$ into the flow $\mathrm{Qu}^{\text {Tot }}$ controlled by a stop sign, $\mathrm{T}$ is assumed as $\mathrm{T}=5.5 \mathrm{~s}$. By means of the values of $\mathrm{V}$ and $\delta$ previously indicated, with $\mathrm{T}=5.5 \mathrm{~s}$ from (3) the acceleration $a$ kept while merging can be obtained as follows a $=1.2 \mathrm{~m} / \mathrm{s}^{2}$.

By means of $\mathrm{T}=5.5 \mathrm{~s}$ from (2) it is possible to obtain for the stop-controlled slip lane capacity $\mathrm{C}_{\mathrm{E}, \mathrm{R}}$ the values in function of $\mathrm{Qu}^{\mathrm{Tot}}$ shown in Figure 3. These values are well least-squares interpreted from the relation:

$$
C_{E, R}=1231,4 \cdot e^{-0,0012 \cdot Q u^{T o t}} \quad\left(\mathrm{R}^{2}=0.91\right)
$$

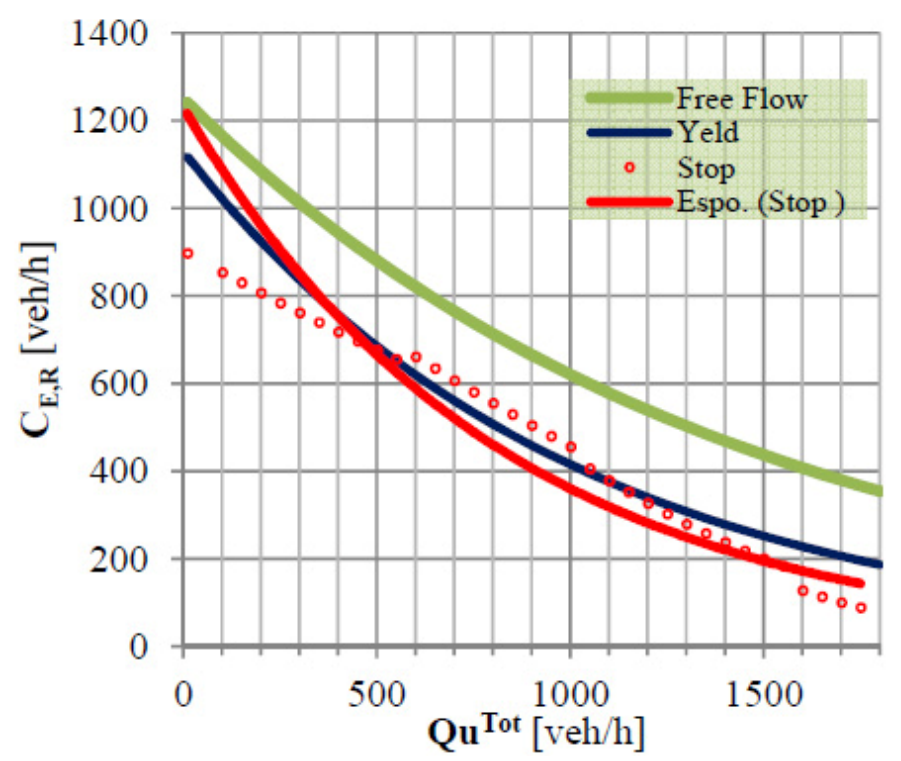

Figure 3. Free Flow, Yeld and Stop slip lane capacity 


\subsection{Right-turn Yield Slip Lanes}

In this case the geometric layout is similar to that of stop-controlled slip lanes (Figure 2); the capacity formula is described in NCHRP Report 672:

$$
C_{E, R}=1130 \cdot e^{-0,001 \cdot Q u^{T o t}}
$$

It is illustrated in Figure 3 along with the stop-controlled slip lane capacity. Figure 3 shows that the yield slip lane capacity is usually higher than that with a stop control.

\section{Slip Lane with an Entry Lane (Free-flow Slip Lane)}

This slip lane type is generally shown as in Figure 4. There are free-flow slip lane configurations which have an exit section as short as $30 \mathrm{~m}$, for instance as provided for by Polish Road Intersections Design Guidelines - Part II, 2001. As in stop and yield-controlled slip lanes, the right-turn flow into the slip lane is denoted with $\mathrm{Q}_{\mathrm{E}, \mathrm{R}}{ }^{\text {bypass}}$; the antagonist flow of $\mathrm{Q}_{\mathrm{E}, \mathrm{R}}^{\text {bypass }}$ from the roundabout is indicated with $\mathrm{Qu}^{\mathrm{Tot}}$ (Figure 4).

The HCM 2010 Manual for free-flow slip lanes does not provide the capacity formulations but it qualitatively estimates capacity values higher than those obtained by Yeld-controlled slip lanes. The following relation (6) has been obtained from Tracz (Tracz, 2008; Tracz et al., 2011) for free-flow slip lanes at single-lane roundabouts:

$$
C_{E, R}=1250 \cdot e^{-0,0007 \cdot Q u^{T o t}}
$$

The relation (6) is illustrated in Figure 3.

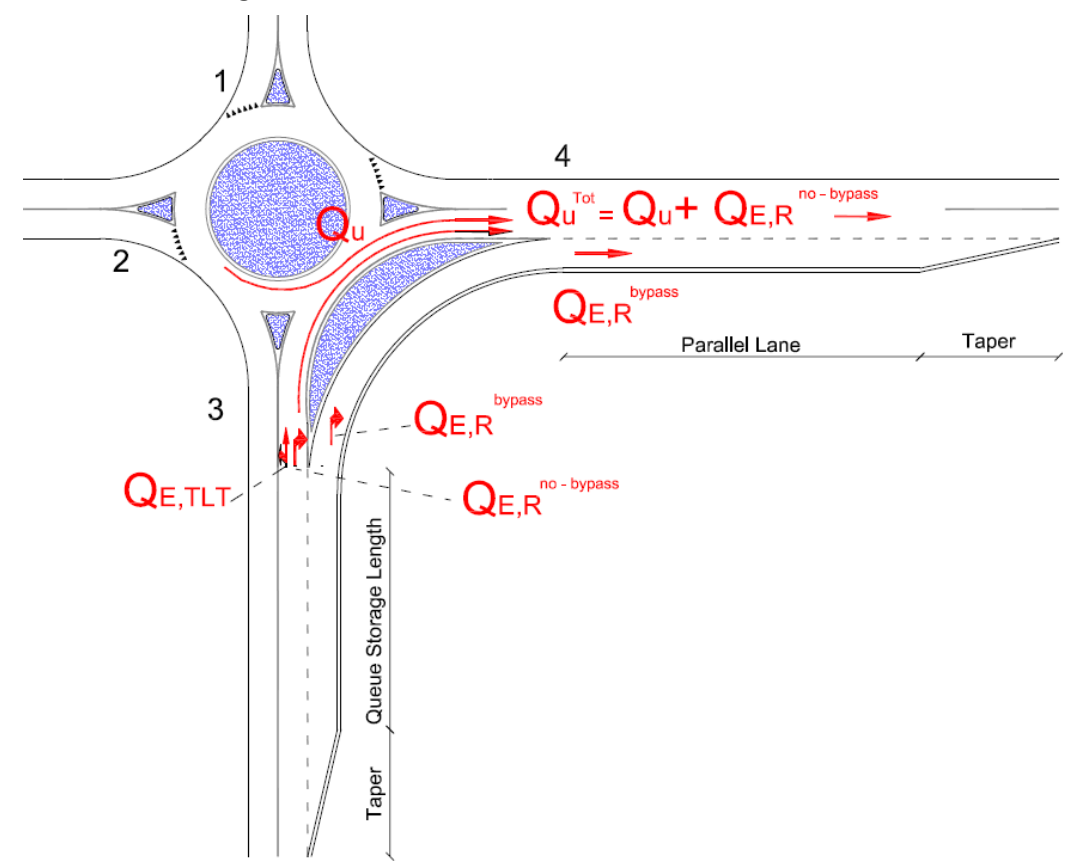

Figure 4. Entry, circulating and exit flows at roundabout (free flow bypass lane)

\section{Effect of Pedestrian Flow on Slip Lane Capacity}

The presence of pedestrian crossings reduces entry and exit capacity of slip lanes (there are generally 2 pedestrian crossings at each slip lane: the former that lies adjacent to the entry to the roundabout, the latter at the exit leg). In order to take these entry effects into consideration, the analyses carried out in this paper have adopted Brilon's formula (Brilon et al., 1993):

$$
\begin{gathered}
C_{E, R}{ }^{\text {ped-Entry }}=C_{0} \cdot M_{E, R}{ }^{\text {Entry }} \\
M_{E, R}{ }^{E n t y}=\left(1119,5-0,715 \cdot Q_{u}^{T o t}-0,644 \cdot \mathrm{Q}_{\mathrm{ped}}{ }^{\text {Entry }}+0,00073 \cdot Q_{u}{ }^{\text {Tot }} \cdot \mathrm{Q}_{\mathrm{ped}}{ }^{\text {Enty }}\right) /\left(1069-0,65 \cdot Q_{u}{ }^{\text {Tot }}\right)
\end{gathered}
$$

where:

$\mathrm{M}_{\mathrm{E}, \mathrm{R}}^{\text {Entry }}=$ right-turn lane pedestrian capacity reduction factor; 
$\mathrm{C}_{\mathrm{E}, \mathrm{R}}{ }^{\text {ped-Entry }}=$ by-pass capacity, impact of pedestrians considered at Entry [veh/h];

$\mathrm{C}_{0}=$ slip lane capacity assumed as equal as $1250 \mathrm{veh} / \mathrm{h}$ (generally, $\mathrm{C}_{0}$ value ranges from 1200 to $1400 \mathrm{veh} / \mathrm{h}$ );

$\mathrm{Q}_{\text {ped }}{ }^{\text {Entry }}=$ pedestrian flow at Entry $[\mathrm{ped} / \mathrm{h}]$

In order to determine the slip lane capacity at pedestrian crossings in roundabout exit legs $\mathrm{C}_{\mathrm{E}, \mathrm{R}}{ }^{\text {ped-Exit }}$, Marlow and Maycock formula (Marlow \& Maycock, 1982) has been adopted:

$$
\begin{aligned}
& C^{\text {ped-Exit }}=\frac{\mathrm{Q}_{\text {ped }}^{E x i t}}{\mathrm{Q}_{\mathrm{ped}}^{E x i t} \cdot \beta+\left(e^{Q_{\text {ped }}^{\text {Ext }} \cdot \cdot \alpha}-1\right) \cdot\left(1-e^{-\mathrm{Q}_{\mathrm{ped}}^{E \text { Ext }} \cdot \beta}\right)} \cdot 3600 \\
& \beta=\frac{1}{C_{E, R} \text { ped-Entry }} \\
& \alpha=\frac{B}{v_{\text {ped }}} \\
& R=\frac{C^{\text {ped-Exit }}}{C_{0}} \\
& M_{E, R}{ }^{E x i t}=\frac{R^{N+2}-R}{R^{N+2}-1} \\
& C_{E, R}^{\text {ped-Exit }}=C_{0} \cdot M_{E, R}^{\text {Exit }}
\end{aligned}
$$

where:

$\mathrm{C}^{\text {ped-Entry }}=$ capacity in the presence of only pedestrian traffic;

$\mathrm{V}_{\text {ped }}=$ average speed of the pedestrian traffic [m/s], generally equal to $1.4 \mathrm{~m} / \mathrm{s}$ on average;

$\mathrm{B}=$ length of a pedestrian crossing $[\mathrm{m}]$;

$\mathrm{C}_{0}=$ slip lane capacity assumed as equal as $1250 \mathrm{veh} / \mathrm{h}$ (generally, $\mathrm{C}_{0}$ value ranges from 1200 to $1400 \mathrm{veh} / \mathrm{h}$ );

$\mathrm{N}=$ number of vehicles queuing in the area between the pedestrian crossing and the yield line. $\mathrm{N}$ is function of a median longitudinal space occupied by a vehicle (equal to $5 \div 6 \mathrm{~m}$ ).

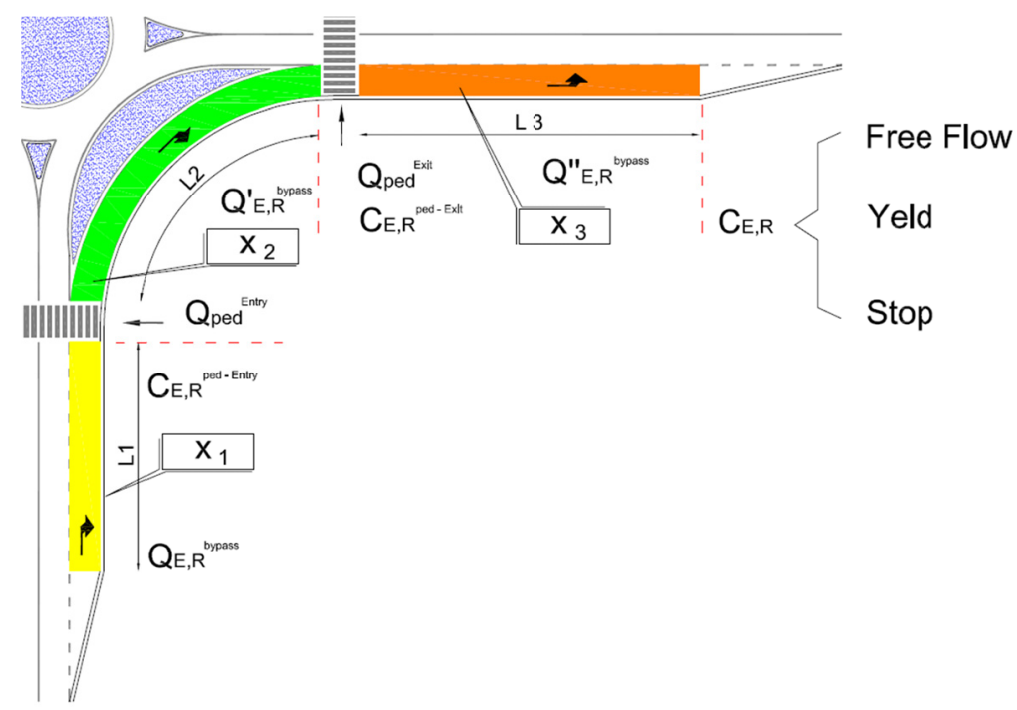

Figure 5. Flows, capacities and degree of saturation on slip lane

The presence of the two pedestrian crossings on the slip lane (the former on the entry leg, the latter on the exit leg from the roundabout) together with the entry (controlled by stop or yield signs, or free-flow) determines three distinct road sections, each with its own function. More specifically, according to the vehicular direction, there follows one after another (see Figure 5): 
- Section 1 (of length L1) with capacity $\mathrm{C}_{\mathrm{E}, \mathrm{R}}^{\text {ped-Entry }}$, flow $\mathrm{Q}_{\mathrm{E}, \mathrm{R}}$ bypass and saturation degree $\mathrm{x}_{1}$;

- Section 2 (of length L2) with capacity $\mathrm{C}_{\mathrm{E}, \mathrm{R}}{ }^{\text {ped-Exit }}$, flow $\mathrm{Q}^{\prime}{ }_{\mathrm{E}, \mathrm{R}}^{\text {bypass }}$ and saturation degree $\mathrm{x}_{2}$;

- Section 3 (of length L3) with capacity $\mathrm{C}_{\mathrm{E}, \mathrm{R}}$, flow $\mathrm{Q}$ " ${ }_{\mathrm{E}, \mathrm{R}}$ bypass and saturation degree $\mathrm{x}_{3}$;

Since the three sections are in sequence, the following conditions need to be verified:

$$
\begin{aligned}
& x_{1}=\frac{Q_{E, R}^{\text {bypass }}}{C_{E, R}^{\text {ped-Entry }}} \\
& \mathrm{Q}^{\prime}{ }_{\mathrm{E}, \mathrm{R}}^{\text {bypass }}=\min \left(\mathrm{Q}_{\mathrm{E}, \mathrm{R}}{ }^{\text {bypass }} ; \mathrm{C}_{\mathrm{E}, \mathrm{R}}{ }^{\text {ped-Entry }}\right) \\
& x_{2}=\frac{Q_{E, R}^{\prime \text { bypass }}}{C_{E, R}^{\text {ped-Exit }}} \\
& \mathrm{Q}^{\prime}{ }_{\mathrm{E}, \mathrm{R}}^{\text {bypass }}=\min \left(\mathrm{Q}^{\prime}{ }_{\mathrm{E}, \mathrm{R}}{ }^{\text {bypass. }} ; \mathrm{C}_{\mathrm{E}, \mathrm{R}}{ }^{\text {ped-Exit }}\right) \\
& x_{3}=\frac{Q_{E, R^{\text {bypass }}}}{C_{E, R}}
\end{aligned}
$$

where $C_{E, R}$ is calculated by means of expressions (4), (5), (6) according to the slip lane control type. The degree of saturation in a slip lane (required for the estimation of the Total Entry Capacity) corresponds to the maximum value of $\mathrm{x}_{1}, \mathrm{x}_{2}, \mathrm{x}_{3}$ :

$$
\mathrm{x}_{\mathrm{E}, \mathrm{R}}=\max \left(\mathrm{x}_{1}, \mathrm{x}_{2}, \mathrm{x}_{3}\right)
$$

As an example, Figure 6 shows the values of saturation degrees (x1, x2, x3) of a yield-controlled slip lane under varying pedestrian flow intensity $\left(\mathrm{Q}_{\mathrm{ped}}{ }^{\text {Exit }}=50 \div 850 \mathrm{ped} / \mathrm{h}\right)$ in the following traffic conditions: $\mathrm{Q}_{\mathrm{u}}^{\text {Tot }}=800$ $\mathrm{veh} / \mathrm{h}, \mathrm{Q}_{\mathrm{ped}}{ }^{\text {Entry }}=200 \mathrm{ped} / \mathrm{h} ; \mathrm{Q}_{\mathrm{E}, \mathrm{R}}^{\text {bypass }}=600 \mathrm{veh} / \mathrm{h}$. Section L3 (see Figure 5) has also been assumed to be $60 \mathrm{~m}$ long.

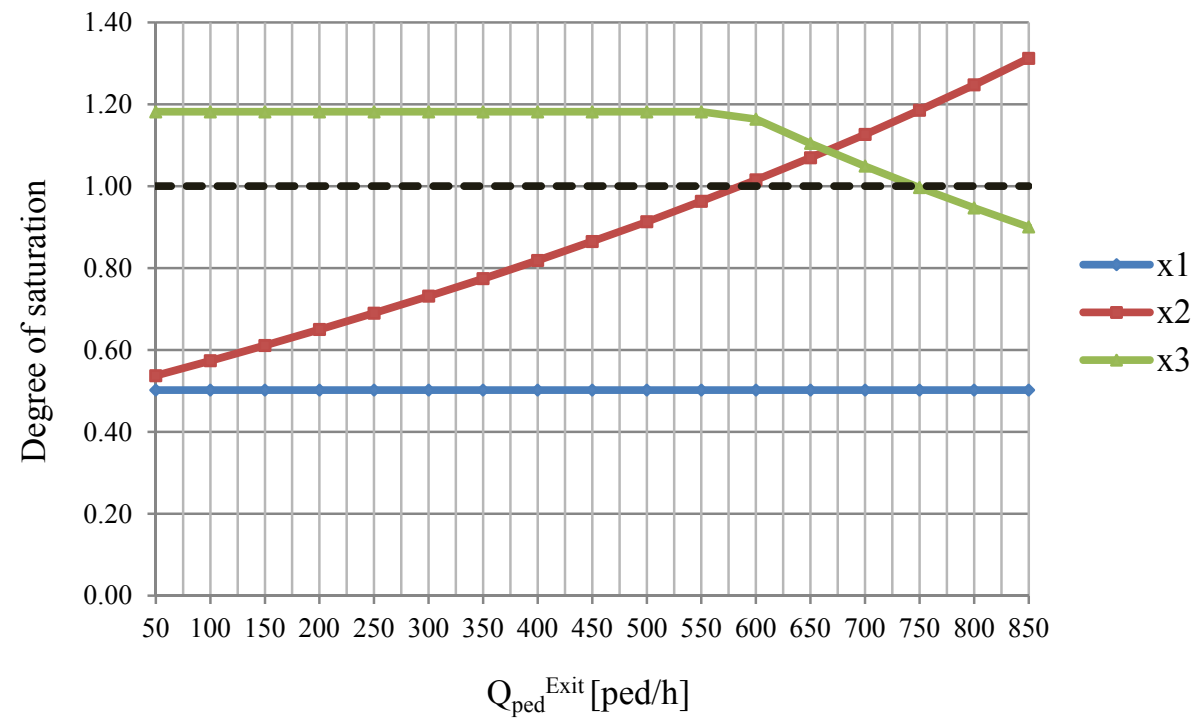

Figure 6. Values of the degree of saturation (bypass with yeld signal)

\section{Capacity of the Merging Lane with the Ring Road}

The entry lane capacity to the ring $\mathrm{C}_{\mathrm{E}, \mathrm{TLT}}$ can be determined through the formulation provided for by the HCM 2010 for roundabouts with a single lane at entries and a single lane at the ring; by denoting the circulating flow with Qc it follows that:

$$
C_{E, T L T}=1130 \cdot e^{\left(-1,0 \cdot 10^{-3}\right) \cdot Q_{c}}
$$

In order to take the pedestrian flow into consideration, Brilon's formula is used (Brilon et al., 1993):

$$
C_{E, T L T}^{\text {ped }}=C_{E, T L T} \cdot M_{E, T L T}
$$




$$
M_{E, T L T}=\left(1119,5-0,715 \cdot Q_{\mathrm{c}}-0,644 \cdot \mathrm{Q}_{\mathrm{ped}}+0,00073 \cdot Q_{\mathrm{c}} \cdot \mathrm{Q}_{\mathrm{ped}}\right) /\left(1069-0,65 \cdot Q_{\mathrm{c}}\right)
$$

$\mathrm{M}_{\mathrm{E}, \mathrm{TLT}}=$ through and left-turn lane pedestrian capacity reduction factor;

$\mathrm{C}_{\mathrm{E}, \mathrm{TLT}}{ }^{\text {ped }}=$ through and left-turn lane vehicle capacity, impact of pedestrians considered [veh/h];

$\mathrm{C}_{\mathrm{E}, \mathrm{TLT}}=$ through and left-turn lane vehicle capacity (no pedestrians crossing, only vehicles) [veh/h];

The respective saturation degree of a lane is given by:

$$
x_{E, T L T}=\frac{Q_{E, T L T}+Q_{E, R}^{\text {no-bypass }}}{C_{E, T L T}^{p e d}}
$$

\section{Total Entry Capacity}

After obtaining the entry lane capacity of a slip lane, by denoting the saturation degrees (entry flow/capacity ratio) with $\mathrm{x}$, the entry capacity $\left(\mathrm{C}_{\mathrm{E}}{ }^{\text {ped }}\right)$ can be estimated through the following relation (Mauro \& Branco, 2010; Corriere \& Guerrieri, 2012; Giuffrè et al., 2012):

$$
C_{E}^{p e d}=\frac{\left(Q_{E, R}+Q_{E, T L T}\right)}{\max \left[x_{E, R} ; x_{E, T L T}\right]}
$$

Where $Q_{E, R}, Q_{E, T L T}, x_{E, R}, x_{E, T L T}$ are respectively flows and degree of saturation at the two lanes of the entry E.

\section{Determination of Delays, Levels of Service and Length of the Queue}

Once the capacity and saturation degrees of entry lanes have been obtained, it is possible to determine the delays and the levels of service for each lane and the entry itself. To this end, the following relations contemplated by the Manual HCM 2010 can be applied, suitably modified to take any pedestrian flow into consideration:

$$
\begin{aligned}
& D_{E, T L T}^{p e d}=\frac{3600}{C_{E, T L T}{ }^{p e d}}+900 \cdot T \cdot\left[\frac{Q_{E, T L T}}{C_{E, T L T}{ }^{p e d}}-1+\sqrt{\left(\frac{Q_{E, T L T}}{C_{E, T L T}{ }_{p e d}}-1\right)^{2}+\frac{\left(\frac{3600}{C_{E, T L T}{ }^{p e d}}\right) \cdot\left(\frac{Q_{E, T L T}}{C_{E, T L T}}\right)}{450 \cdot T}}\right]+5 \cdot \min \left[\frac{Q_{E, T L T}}{C_{E, T L T}}, 1\right] \\
& D_{E, R}^{p e d}=\frac{3600}{C_{E, R}{ }^{p e d}}+900 \cdot T \cdot\left[\frac{Q_{E, R}}{C_{E, R}{ }^{p e d}}-1+\sqrt{\left(\frac{Q_{E, R}}{C_{E, R} p e d}-1\right)^{2}+\frac{\left(\frac{3600}{C_{E, R} p e d}\right) \cdot\left(\frac{Q_{E, R}}{C_{E, R}}\right)}{450 \cdot T}}\right]+5 \cdot \min \left[\frac{Q_{E, R}}{C_{E, R}{ }^{p e d}}, 1\right] \\
& D_{E}{ }^{\text {ped }}=\frac{D_{E, R}{ }^{\text {ped }} \cdot Q_{E, R}+D_{E, T L T}^{\text {ped }} \cdot Q_{E, T L T}}{Q_{E, R}+Q_{E, T L T}}
\end{aligned}
$$

where $\mathrm{D}_{\mathrm{E}, \mathrm{R}}^{\text {ped }}, \mathrm{Q}_{\mathrm{E}, \mathrm{R}}, \mathrm{D}_{\mathrm{E}, \mathrm{TLT}}^{\text {ped }}, \mathrm{Q}_{\mathrm{E}, \mathrm{TLT}}$ are respectively delays and flow rates at the two lanes of the entry $\mathrm{E}$. $\mathrm{T}$ is the reference time $(\mathrm{T}=1$ for 1 -hour analysis; $\mathrm{T}=0.25$ for 15 -minute analysis). The levels of service referred to the delay values obtained by means of the previous relations (26), (27) and (28) are shown in Table 1 (HCM, 2010).

As an example, Figure 7 below indicates the value assumed by the mean control delay for an entry to the roundabout with a slip lane under varying saturation degrees in the following traffic conditions: $\mathrm{Q}_{\mathrm{c}}=750 \mathrm{veh} / \mathrm{h}$; $\mathrm{Q}_{\text {ped }}{ }^{\text {Entry }}=50 \mathrm{ped} / \mathrm{h} ; \mathrm{Q}_{\text {ped }}{ }^{\text {Exit }}=50 \mathrm{ped} / \mathrm{h} ; \mathrm{Q}_{\mathrm{u}}{ }^{\text {Tot }}=500 \mathrm{veh} / \mathrm{h}$. Whenever traffic changes, surfaces similar to those in Figure 7 are obtained.

Table 1. Level of service

\begin{tabular}{ccc}
\hline $\begin{array}{c}\text { Control } \\
\text { Delay }\end{array}$ & $\mathrm{Q} / \mathrm{C} \leq 1$ & $\mathrm{Q} / \mathrm{C} \geq 1$ \\
\hline $0-10$ & $\mathrm{~A}$ & $\mathrm{~F}$ \\
$10-15$ & $\mathrm{~B}$ & $\mathrm{~F}$ \\
$15-25$ & $\mathrm{C}$ & $\mathrm{F}$ \\
$25-35$ & $\mathrm{D}$ & $\mathrm{F}$ \\
$35-50$ & $\mathrm{E}$ & $\mathrm{F}$ \\
$>50$ & $\mathrm{~F}$ & $\mathrm{~F}$ \\
\hline
\end{tabular}




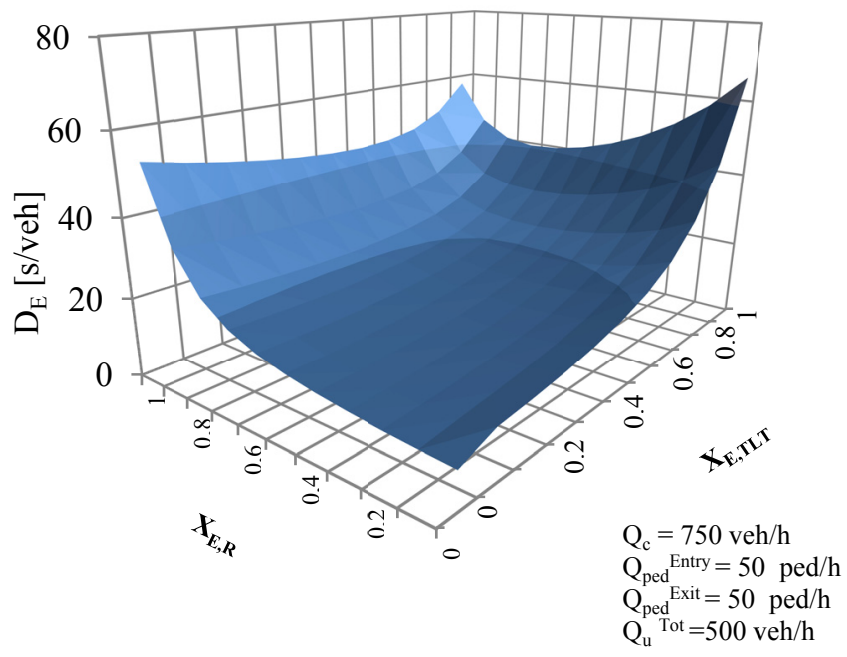

Figure 7. Entry mean control delay

\section{Functional Comparison}

In order to identify the traffic conditions which make roundabouts with a right-turn slip lane more advantageous than conventional roundabouts in terms of functionality, specific analyses have been carried out for different O/D matrices. It is noteworthy to point out that if there is a right-turn slip lane at each leg, the functional geometric layout has the same behaviour as in flower roundabouts (see Figure 1c).

The geometric layouts compared to one another are the following:

- $\quad$ Roundabouts with stop-controlled slip lanes (at each leg);

- Roundabouts with yield-controlled slip lanes (at each leg);

- $\quad$ Roundabouts with Free-flow slip lanes (at each leg);

- Conventional roundabouts with a single lane at entries and a single lane at the ring - layout $(1+1)$;

- Conventional roundabouts with a single lane at entries and a double lane at the ring - layout $(1+2)$;

- Conventional roundabouts with a double lane at entries and a double lane at the ring - layout $(2+2)$.

In order to determine the capacities, the following formulations have been used:

- Equation (4) for roundabouts with a stop-controlled slip lane;

- $\quad$ Equation (5) for roundabouts with a yield-controlled slip lane;

- Equation (6) for roundabouts with a free-flow slip lane;

- The formula suggested by the HCM 2010 Manual for conventional roundabouts with a single lane at entries and 1 lane at the ring - layout $(1+1)$ :

$$
\mathrm{C}_{\mathrm{E}}=1130 \cdot \mathrm{e}^{-0,0001 \cdot \mathrm{Qc}}
$$

- The formula suggested by the HCM 2010 Manual for conventional roundabouts with a single lane at entries and two lanes at the ring - layout $(1+2)$ :

$$
\mathrm{C}_{\mathrm{E}}=1130 \cdot \mathrm{e}^{-0,007 \cdot \mathrm{Qc}}
$$

- The formulas suggested by the HCM 2010 Manual for conventional roundabouts with a double lane at entries and a double lane at the ring - layout $(2+2)$. For the two lanes at entries the formulas are the following:

$$
\begin{aligned}
\mathrm{C}_{\mathrm{E}, \mathrm{R}} & =1130 \cdot \mathrm{e}^{-0,0007 \cdot \mathrm{Qc}} \\
\mathrm{C}_{\mathrm{E}, \mathrm{TLT}} & =1130 \cdot \mathrm{e}^{-0,00075 \cdot \mathrm{Qc}}
\end{aligned}
$$

For each layout under study the mean control delays have been determined by employing Equations (26) (27) and (28). The traffic conditions examined are the following:

- $\quad$ /D Matrices - Origin/destination matrices of traffic flows in percentage terms - (the leg numeration is 
illustrated in Figure 2 and Figure 4): $\rho 1$ considers a majority of vehicles going ahead; the same occurs in $\rho 2$ but left-turn percentages are $25 \%$. Matrix $\rho 3$ indicates a clear majority of crossings for flows 2 and 4 and very limited left-turns, $\rho 4$ e $\rho 5$ indicate two or one direction of preferential exit. Matrix $\rho 6$ assumes that most users turn to the right ( $70 \%$ out of the total);

- Vehicular flow vectors. Q3 flows are basically the same on the four legs, Q2 flows especially move in direction 1-3; Q1 is an intermediate situation between Q3 and Q2; Q4 indicate very unbalanced flows.

- Pedestrian flow vectors: Qp1 and Qp2: pedestrian flows of average/high intensity; Qp3: very low pedestrian flows.

$$
\begin{aligned}
& \rho 1=\left|\begin{array}{cccc}
0 & 0,15 & 0,74 & 0,11 \\
0,19 & 0 & 0,24 & 0,57 \\
0,63 & 0,15 & 0 & 0,22 \\
0,19 & 0,74 & 0,07 & 0
\end{array}\right| \quad \rho 2=\left|\begin{array}{cccc}
0 & 0,15 & 0,60 & 0,25 \\
0,2 & 0 & 0,20 & , 55 \\
0,60 & 0,25 & 0 & 0,15 \\
0,30 & 0,50 & 0,20 & 0
\end{array}\right| \\
& \rho 3=\left|\begin{array}{cccc}
0 & 0,15 & 0,70 & 0,15 \\
0,02 & 0 & 0,18 & 0,80 \\
0,70 & 0,15 & 0 & 0,15 \\
0,18 & 0,80 & 0,02 & 0
\end{array}\right| \quad \rho 4=\left|\begin{array}{cccc}
0 & 0,125 & 0,75 & 0,125 \\
0,375 & 0 & 0,375 & 0,25 \\
0,75 & 0,125 & 0 & 0,125 \\
0,375 & 0,25 & 0,375 & 0
\end{array}\right| \\
& \rho 5=\left|\begin{array}{cccc}
0 & 0,25 & 0,75 & 0,125 \\
0,125 & 0 & 0,625 & 0,25 \\
0,5 & 0,25 & 0 & 0,25 \\
0,125 & 0,25 & 0,625 & 0
\end{array}\right| \quad \rho 6=\left|\begin{array}{cccc}
0 & 0,7 & 0,2 & 0,1 \\
0,2 & 0 & 0,7 & 0,1 \\
0,1 & 0,3 & 0 & 0,6 \\
0,7 & 0,2 & 0,1 & 0
\end{array}\right| \\
& {[Q 1]=\left[\begin{array}{llll}
300 & 200 & 500 & 400
\end{array}\right]} \\
& {[\mathrm{Q} 2]=\left[\begin{array}{llll}
386 & 182 & 410 & 446
\end{array}\right]} \\
& {[\mathrm{Q} 3]=\left[\begin{array}{llll}
436 & 428 & 410 & 446
\end{array}\right]} \\
& {[\mathrm{Q} 4]=\left[\begin{array}{llll}
100 & 500 & 100 & 500
\end{array}\right]} \\
& {[\mathrm{Qp} \mathrm{1}]=\left[\begin{array}{llll}
50 & 100 & 50 & 100
\end{array}\right]} \\
& \text { [Qp 2] }=\left[\begin{array}{llll}
150 & 300 & 150 & 300
\end{array}\right] \\
& \text { [Qp 3] }=\left[\begin{array}{llll}
10 & 10 & 10 & 10
\end{array}\right]
\end{aligned}
$$

For each traffic condition examined, the vehicle flows entering the roundabout have been increased from value 0 to the value which determines the reaching of the roundabout simple capacity with regard to the geometric design which, each time, offers the highest capacity. It is noted that roundabouts with slip lane allow a significant delay reduction in all the flow conditions compared to conventional roundabouts with a single lane at entries (layouts $(1+1)$ and $(1+2))$. On the contrary, compared with multilane roundabouts $(2+2)$ their performances are lower, up to $70 \%$ of the total right-turn flows. Once such a threshold is exceededand according to the pedestrian flow intensity, it can be more convenient to use slip lane roundabouts than all the other designs. Moreover, free-flow slip lanes prove to be more advantageous than those controlled by stop or yield signs; this is consistent with the results shown by Al-Ghandour (Al-Ghandour et al., 2012). The following figures elucidate the above points. More specifically, if right-turn percentage is lower than $70 \%$ (Figures $8,9,10$ and 11), roundabouts with slip lanes cause intermediate delays between roundabouts with the geometric schemes $(1+2)$ and $(2+2)$. On the contrary, when the right-turn percentage is higher or equal to $70 \%$ of the total (see Figures 12 and 13), slip lane roundabouts can cause delays inferior to those observed in the other configurations examined. In case of moderate pedestrian flow (Qp3), only roundabouts with free-flow slip lanes can cause delays inferior to those with double lanes. If, on the contrary, the pedestrian flow is high (Qp2), the performances of roundabouts with right-turn bypass lanes are the best among all the configurations, regardless of their control type. 


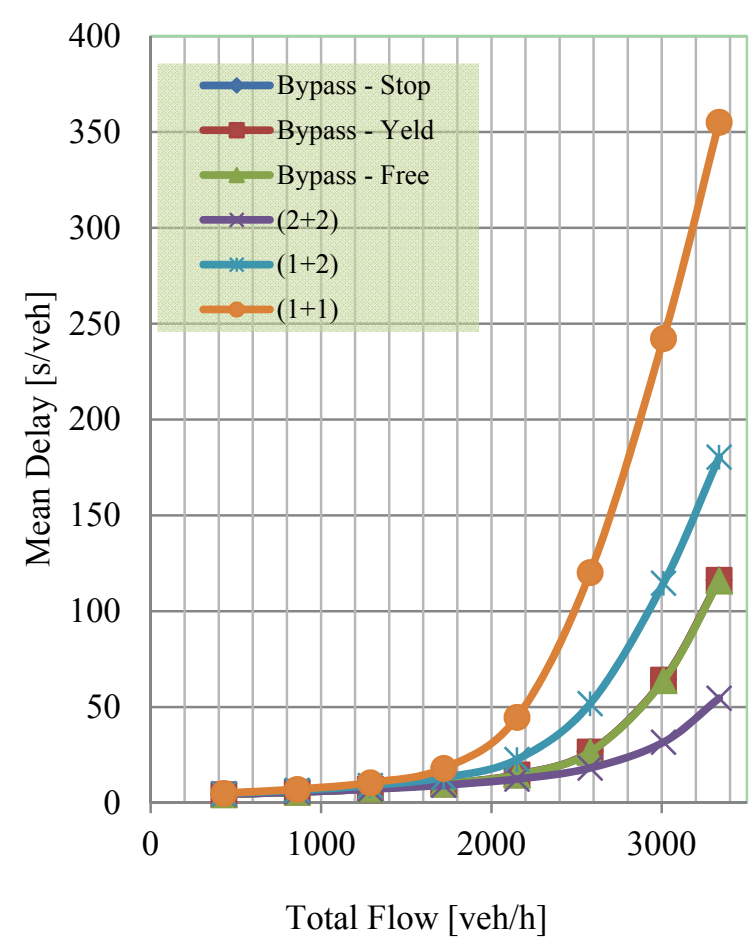

Figure 8. Roundabouts mean delay - Scenario: $\rho 1$, Q1, Qp1

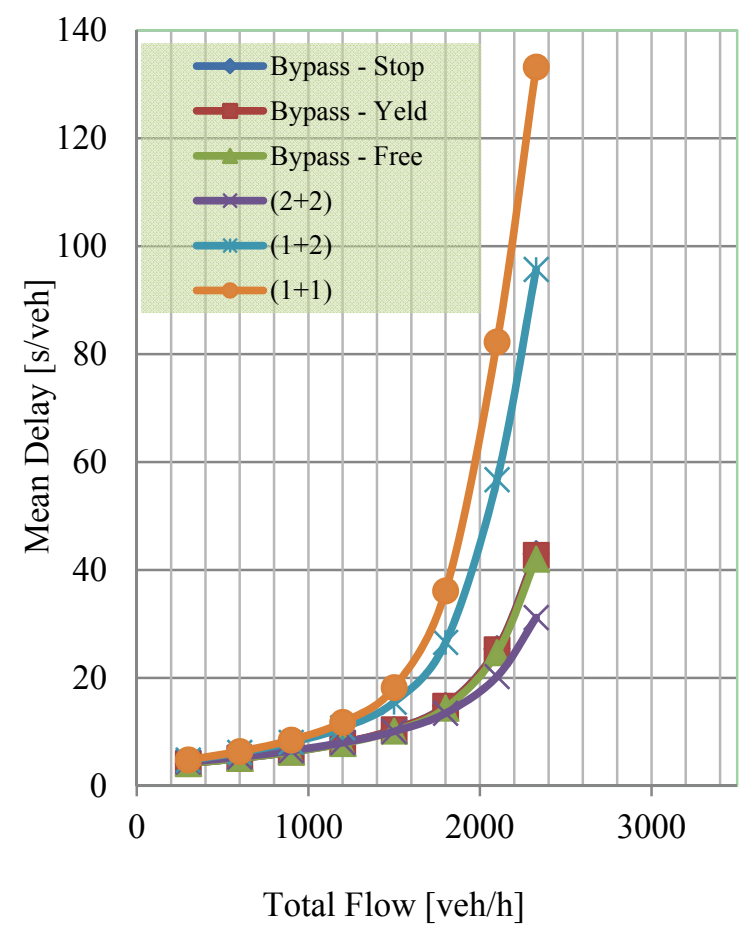

Figure 10. Roundabouts mean delay - Scenario: $\rho 1, Q 3$, Qp2

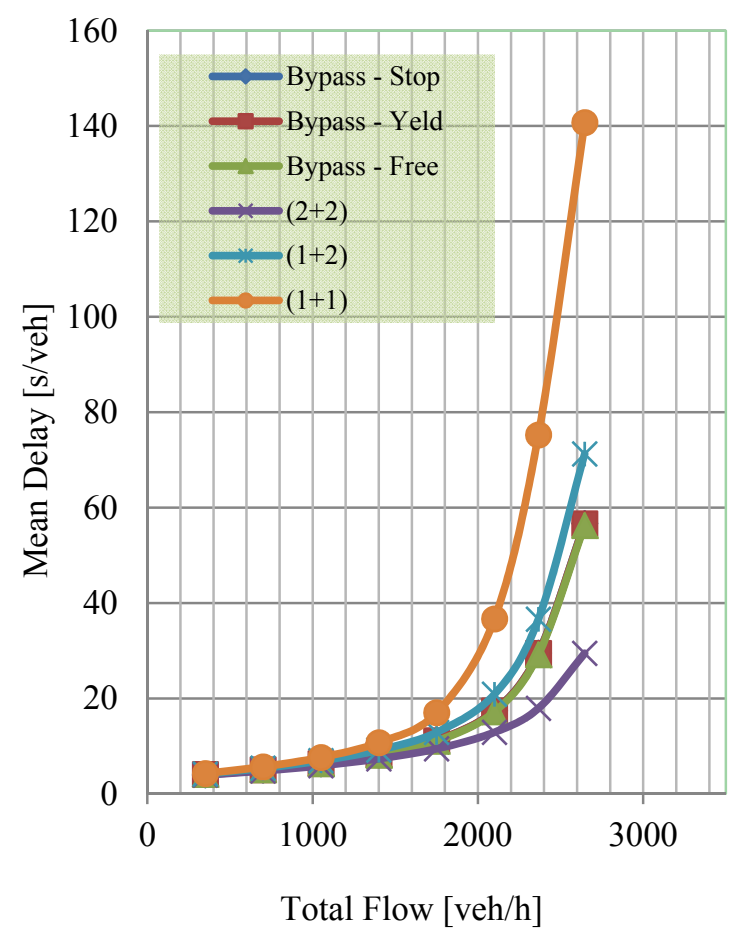

Figure 9. Roundabouts mean delay - Scenario: $\rho 1$, Q1, Qp2

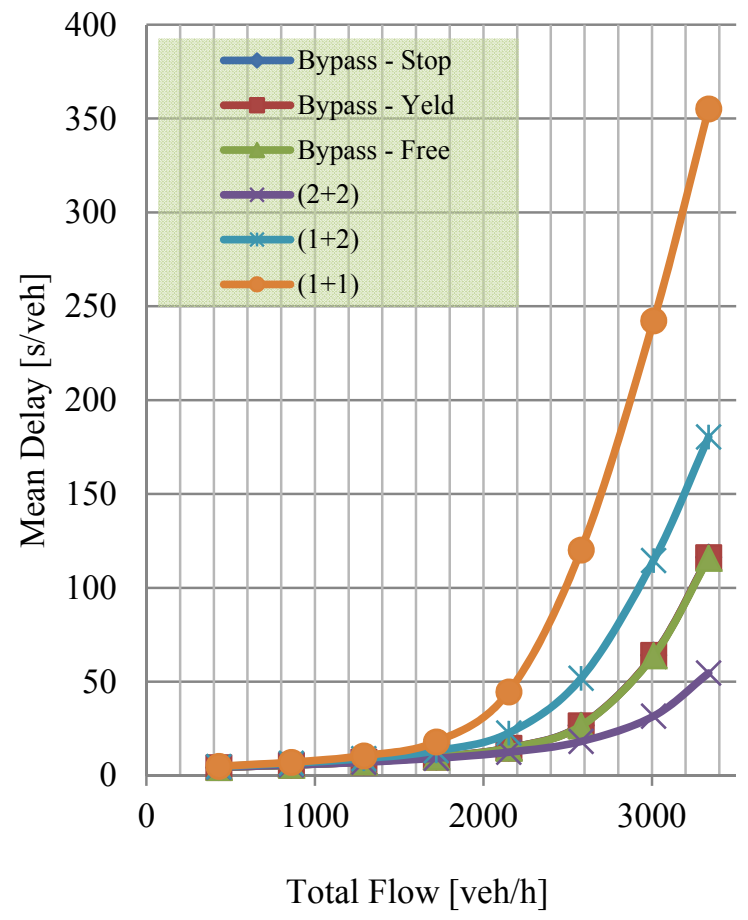

Figure 11. Roundabouts mean delay - Scenario: $\rho 4$, Q3, Qp2 


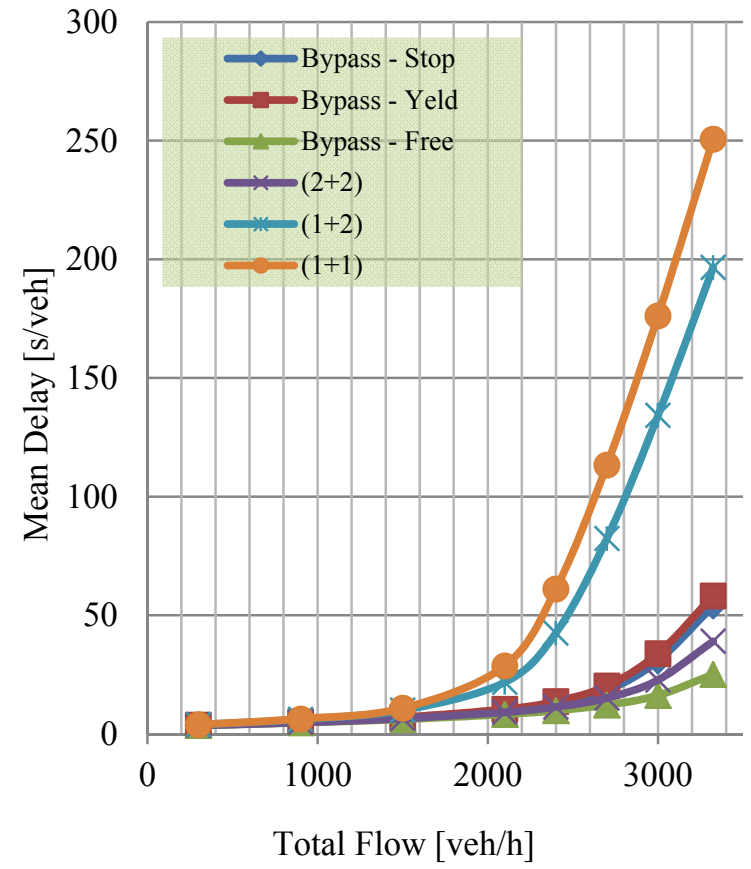

Figure 12. Roundabouts mean delay - Scenario: $\rho 6$, Q4, Qp3

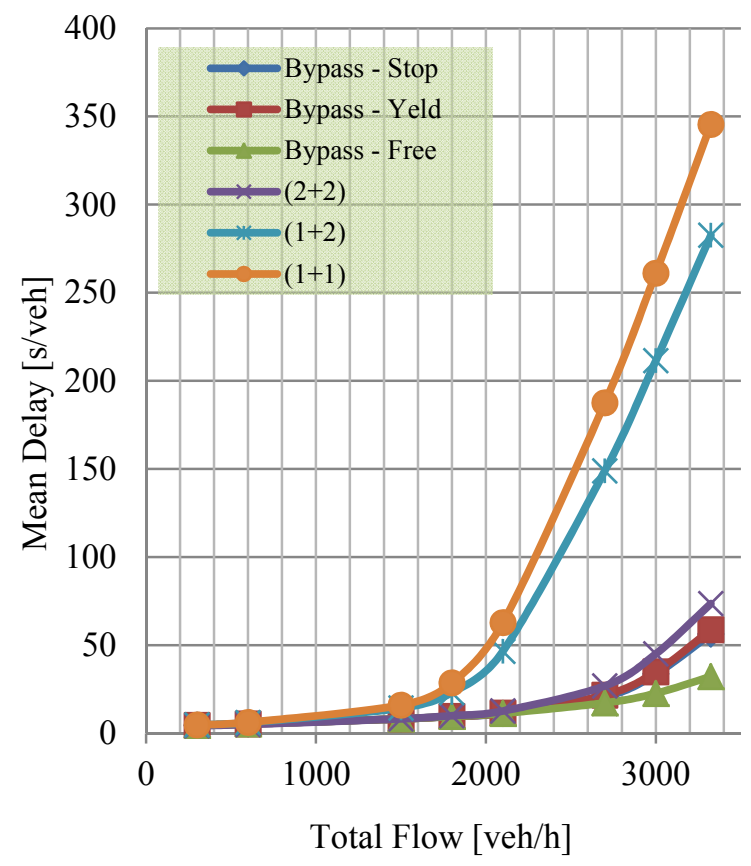

Figure 13. Roundabouts mean delay - Scenario: 06, Q4, Qp2

As for the effects of the distribution of right-turn flows on vehicle delays, also the case in which $\mathrm{Q}_{\mathrm{E}, \mathrm{R}}{ }^{\text {no-bypass }} \neq 0$ has been estimated. It follows that: $\mathrm{Q}_{\mathrm{E}, \mathrm{R}}{ }^{\text {bypass }}=\alpha^{\prime} \cdot \mathrm{Q}_{\mathrm{E}, \mathrm{R}} ; \mathrm{Q}_{\mathrm{E}, \mathrm{R}}{ }^{\text {no-bypass }}=\beta \cdot \mathrm{Q}_{\mathrm{E}, \mathrm{R}}\left(0 \leq \alpha^{\prime} \leq 1 ; 0 \leq \beta \leq 1 ; \alpha+\beta=1\right)$. It has been observed that if right-turn manoeuvres prevail (like, for instance, with matrix $\rho 6$ ) and with high pedestrian flows (Qp2), the distribution of right-turn flows between slip lanes and entry lanes can result in a modest reduction of average intersection delays. For instance, for $\rho 6$, Q4, Qp2, in case of $\alpha^{\prime}=0.6$ there is a maximum benefit of 2 seconds, as shown in Table 2 (yield-controlled slip lane compared to the case in which $\alpha$ ' $=1$ ). Such a circumstance can be explained by the fact that when $\alpha^{\prime}<1$, if on the one hand there is a delay reduction in slip lanes, on the other there is a delay increase in lanes entering the roundabout.

Table 2. Values of the intersection mean delay [s/veh] as function of $\alpha$ '

\begin{tabular}{ccccccc}
\hline Total Entry & \multicolumn{3}{c}{$(\rho 6, \mathrm{Q} 4, \mathrm{Qp} 2) ; \alpha^{\prime}=1$} & \multicolumn{2}{c}{$(\rho 6, \mathrm{Q} 4, \mathrm{Qp} 2) ; \alpha^{\prime}=0,6$} \\
\cline { 2 - 7 } Flow [veh/h] & Stop & Yeld & Free & Stop & Yeld & Free \\
\hline 300 & 5 & 5 & 5 & 4 & 4 & 4 \\
600 & 5 & 5 & 5 & 5 & 5 & 5 \\
1500 & 8 & 8 & 8 & 7 & 7 & 7 \\
1800 & 10 & 10 & 10 & 9 & 9 & 8 \\
2100 & 11 & 12 & 11 & 11 & 11 & 10 \\
2700 & 21 & 22 & 17 & 22 & 20 & 15 \\
3000 & 34 & 35 & 23 & 38 & 33 & 22 \\
\hline
\end{tabular}

\section{Conclusions}

Right-turn slip lanes are employed to increase the capacity of roundabouts. Generally, the slip lane roundabout performances are evaluated through traffic simulations implemented with specialized software. This paper suggests a closed-form model for calculating the capacity and delays in slip lane roundabouts which takes into consideration a great number of geometric and traffic-regulating parameters, among which, slip lane dimensions, traffic control type (stop sign, yield sign, Free Flow), intensity and distribution of vehicle and pedestrian flows, saturation degrees of the lanes and so on. In order to examine the traffic conditions which can benefit from slip lane roundabouts in terms of capacity and delays, compared to traditional schemes which have no additional lanes, a great number of analyses have been carried out by considering different O/D matrices and vehicle and 
pedestrian flow vectors. The results of the analyses show that roundabouts with right-turn bypass lane lead to a significant delay reduction in any flow condition compared to conventional roundabouts with one lane at entries $((1+1)$ or $(1+2)$ layouts). Compared to multilane roundabouts ( 2 ring lanes +2 entry lanes), slip lane roundabouts cause more serious delays, in the case of right-turn flows up to $70 \%$ of the total. When such a threshold is exceeded slip lane roundabouts appear to be more convenient than any other design, in that the average vehicle delays decrease in a more and more marked manner in the presence of the same traffic volume. Moreover, among the slip lane types, those with a free-flow lane are more advantageous than those with a stop or yield sign. Finally, we have observed that the distribution of right-turn flows between a slip lane and a lane entering the roundabout $\left(\alpha^{\prime}<1\right)$ can cause a slight reduction in the average intersection delays; this exclusively happens when the right-turn percentage is higher than $70 \%$.

\section{References}

Al-Ghandour, M., Schroeder, B., Rasdorf, W., \& Williams, B. (2012). Delay Analysis of Single-Lane Roundabout with a Slip Lane under Varying Exit Types. Experimental Balanced Traffic Volumes, and Pedestrians: Using Microsimulation, TRB, Annual Meeting.

Brilon W., Stuwe B., \& Drews O. (1993). Sicherheit und Leistungsfähigkeit von Kreisverkehrsplätzen. Institute for Traffic Engineering, Ruhr Universität, Bochum (Deutschland).

Corriere, F., \& Guerrieri, M. (2012). Performance analysis of basic turbo-roundabout in urban context. Procedia - Social and Behavioral Sciences, 53(3), 622-632. http://dx.doi.org/10.1016/j.sbspro.2012.09.912

FHWA. (2004). Pedestrian Safety Guide and Countermeasure Selection System (PEDSAFE). Improved Right-Turn Slip-Lane Design. Report No. FHWA-SA-04-003.

Fortuijn, L. G. H. (2009). Turbo Roundabouts: Estimation of Capacity. Transportation Research Record, 2130(2009), 83-92. http://dx.doi.org/10.3141/2130-11

Giuffrè, O., Granà, A., \& Marino, S. (2012). Comparing Performances of Turbo-roundabouts and Double-lane Roundabouts. Modern Applied Science, 6(10), 70-79. http://dx.doi.org/10.5539/mas.v6n10p70

HCM. (2010). Highway Capacity Manual (ed.). Transportation Research Board, TRB.

Khintchine, A. Y. (1932). Mathematical theory of a stationary queue. Matematicheskii Sbornik, 39(4).

Kleinlock, L. (1975). Queuing Systems, I. New York: John Wiley and Sons.

Mauro, R., \& Branco, F. (2010). Comparative Analysis of Compact Multilane Roundabouts and Turbo-Roundabouts. Journal of Transportation Engineering, 136(4), 316-322. http://dx.doi.org/10.1061/(ASCE)TE.1943-5436.0000106

Mauro, R., \& Cattani, M. (2012). Functional and Economic Evaluations for Choosing Road Intersection Layout. Promet-Traffic \& Transportation, 24(5). http://dx.doi.org/10.7307/ptt.v24i5.1180

Mauro, R., \& Branco, F. (2012). Two Vehicular Headways Time Dichotomic Models. Modern Applied Science, 6(12), 1-12. http://dx.doi.org/10.5539/mas.v6n12p1

Marlow, M., \& Maycock, G. (1982). The Effect of Zebra Crossings on Junction Entry Capacities. Report SR 742, Transport and Road Research Laboratory (TRRL), Crowthorne, Berkshire, England.

NCHRP Report 672. (2010). Roundabouts: An Informational Guide - Second Edition, TRB.

Pollaczek, F. (1930). Über eine Aufgabe der Wahrscheinlichkeitstheorie. Mathematische Zeitschrift.

Tollazzi, T., Renčelj, M., \& Turnšek, S. (2011). New Type of Roundabout: Roundabout with "Depressed” Lanes for Right Turning - "Flower Roundabout". Promet - Traffic \& Transportation, 23(5), 353-358.

Tracz, M. (2008). Analysis of Small Roundabouts' Capacity. National roundabout conference, Kansas City, Missouri.

Tracz, M., Chodur, J., \& Ostrowsk, K. (2011). Roundabouts Country report - Poland. $6^{\text {th }}$ International Symposium on Highway Capacity and Quality of Service, Stockholm.

Turborotondes, CROW publicatie 257, April 2008.

Wytyczne Projektowania Skrzyzowan Drogowych, Czesc II. (2001). Warszawa (Road intersections design guidelines - Part II). 